\title{
Simulation of Game Model for Supply Chain Finance Credit Risk Based on Multi-Agent
}

\author{
Yueliang Su, Nan Lu \\ School of Business Administration, South China University of Technology, Guangzhou, China \\ Email: 24848451@qq.com
}

Received 19 November 2014; revised 21 December 2014; accepted 28 December 2014

Copyright (C) 2015 by authors and Scientific Research Publishing Inc.

This work is licensed under the Creative Commons Attribution International License (CC BY). http://creativecommons.org/licenses/by/4.0/

(c) (i) Open Access

\begin{abstract}
Supply chain finance is an efficient method to solve SME's financing problem. A core issue is to simulate the supply chain finance system's real operations. To solve the problem, this paper designs a simulation model for supply chain finance based on Simon's bounded rationality with multiagent simulation technique instead of absolute rationality. The influences of the behaviors of bank, SME and warehousing company on credit risk of the supply chain finance are simulated and managerial insights are given. The research can help to reduce credit risk of bank loan while increasing the supply chain system's benefit.
\end{abstract}

\section{Keywords}

Supply Chain Finance, Credit Risk, Game, Simulation

\section{Introduction}

Supply chain finance is a financial service that using controllable credit risk of the whole supply chain, instead of the uncontrollable credit risk of the SME, to solve SME's financing problem. Credit risk is the core problem of supply chain finance.

Berger (2004) [1] is the first one who uses supply chain finance in SME financing, and drives a group of scholars to research the supply chain finance about operation mode, risk management, financing mode, financing products.

In the aspect of risk management, Busch [2] summed up the risk congeries characteristic of supply chain finance's external environment and inside subjects, and put forward that management cost can be greatly reduced if using suitable risk control means. Kerr [3] discussed supply chain finance's cash management based on the combination of trade financing and credit project. Camerinelli [4] analyzed supply chain finance's operation process and pointed out that cash flow can be optimized due to the enhancement of interactions between enter- 
prises, but integrating and managing capital is risky. Buzacott [5] thought about different loan rates and demand uncertainty, then discussed retailer's inventory quantity and financing decision. It can be seen that supply chain finance is more regarded as a mean of financial optimization, and researches about its risk management are usually closely connected with supply chain's structure, trading link and financial management.

Recent years, scholars try to apply the game theory to supply chain finance. Ma J. [6] studied game relationship between bank and SME based on information asymmetry, agency and credit rationing and credit chain. He Q.Y. and Guo T.T. [7] used game theory to analyze SME's financing behavior. Wan D.H. [8] used game theory to discuss the cost-benefit of supply chain finance's special business mode.

As for agent, recently, agent modeling and simulation method is widely used in economic management, and game simulation is a special application of it. Axelrod [9] found that no matter how complex the opponents are, "Tit-for-tat" will eventually win in coopetition. Zhang T. and Sun L.Y. [10] analyzed gamers' individual rationality, then designed an evaluation strategy based onevaluation of the cumulative aspiration tense to simulate the repeated game of several kinds of typical conflict. Liu J.J. and Wang J.Y. [11] took the game model of credit market as an example to study evolutionary game based on multi-agent.

It is observed that applying the game theory in supply chain finance becomes a new research hotspot, this method clearly describes the interests of supply chain finance's business models. However, these researches mainly use traditional game theory to study supply chain finance and still focus on "completely rationality" level, which means the lack of consideration in the supply chain finance's complexity and participants' bounded rationality. Modeling and simulating technique based on agent has been applied extensively in the field of economic, and researches about multi-agent game simulation have scored great achievements, but these theories have not yet combined with the risk management of the supply chain finance. Thus it can be deeply studied, and in this paper, these models are reviewed.

\section{Model Preparation}

In this chap, symbols used in this paper are explained in Table 1, while the credit risk game model based on three-agent (bank, SME and warehousing company) and the gain matrix are given by Table 2.

\begin{tabular}{cccc} 
Table 1. Symbolic hypothesis. & & & \\
\hline Loan amount & $L^{\prime}$ & SME's loan proceeds & $R^{\prime}$ \\
Bank lending rates & $r_{0}$ & SME's loss given default & $T^{\prime}$ \\
Band supervision cost & $C^{\prime}$ & SME's award for sound reputation & $Y^{\prime}$ \\
Movable property pledge rate & $v^{\prime}$ & Warehousing companies' loss given default & $G^{\prime}$ \\
Pledge value & $L^{\prime} / v^{\prime}$ & Warehousing companies' proceeds & $F^{\prime}$ \\
\hline
\end{tabular}

PS: All variables are greater than zero, $L^{\prime} r_{0}-C^{\prime}>0$.

Table 2. Three-agent's game model and gain matrix.

\begin{tabular}{|c|c|c|c|c|c|}
\hline & & \multicolumn{4}{|c|}{ SME } \\
\hline & & Integrity & Default & Integrity & Default \\
\hline \multirow{8}{*}{ Bank } & & & $-L^{\prime}\left(1+r_{0}\right)-C^{\prime}$ & & \\
\hline & & $L^{\prime} r_{0}-C^{\prime}-F^{\prime}$ & $-F^{\prime}+L^{\prime} / v^{\prime}$ & $L^{\prime} r_{0}-C^{\prime}-F^{\prime}$ & $-L^{\prime}\left(1+r_{0}\right)-C^{\prime}-F^{\prime}$ \\
\hline & Loan & $R^{\prime}-L^{\prime} r_{0}+Y^{\prime}$ & $R^{\prime}+L^{\prime}\left(1+r_{0}\right)$ & $R^{\prime}-L^{\prime} r_{0}+Y^{\prime}$ & $R^{\prime}+L^{\prime}\left(1+r_{0}\right)-T^{\prime}-H^{\prime}$, \\
\hline & & $F^{\prime}$ & $-T^{\prime}-L^{\prime} / v^{\prime}$ & $F^{\prime}$ & $F^{\prime}+H^{\prime}-G^{\prime}$ \\
\hline & & & $F^{\prime}$ & & \\
\hline & No loan & $0, Y^{\prime}, 0$ & $0,0,0$ & $0, Y^{\prime}, 0$ & $0,0,0$ \\
\hline & & \multicolumn{2}{|c|}{ Conscientiousness } & \multicolumn{2}{|r|}{ Muting } \\
\hline & & \multicolumn{4}{|c|}{ Warehousing company } \\
\hline
\end{tabular}




\section{The Activity Rules under Optimal Reaction Dynamic}

The optimal reaction (it means that participants can make decisions quickly) dynamic mechanism is applicable to repeated games and evolutionary strategies among a few bounded rationality participants who have quick learning skill. According to the "rules govern decision" mode, this paper designs the "predetermined strategies" rules for the supply chain finance participants: stipulating the behavior guide before the financial activities, then participants make decisions quickly in accordance with the guide during activities.

According to the thought of "optimal reaction" (It means maximum profit), this paper assumes that a participant would regard opponents' previous strategies as the ones they will use this time, then makes decisions in accordance with the behavior guide.

This paper calls the activity rules “'Predetermined strategies” that based on optimal reaction”.

\subsection{The Portfolio of Banks' and SMEs" "Predetermined Strategies"}

Assuming that participants' memory length is single-period game, and in the first game, participants select integrity or default voluntarily (To simplify the description, this paper calls "loan" as "integrity" and "no loan" as "default”); In the next game, participants make decisions according to opponents' previous strategies [12].

Let $p_{1}, p_{2}, p_{3}$ denote the probability of participants selecting integrity in the first game, in the second game if opponents select integrity last time and in the second game if opponents defaulted last time, respectively, $p_{1}$, $p_{2}, p_{3} \in[0,1]$. If limit the probability of integrity to 1 or 0 , and 1 denotes integrity while 0 denotes default, then probability turns into strategy. Dividing the player's strategy into initial strategy and reaction strategy, according to the reaction strategy, participants can be classified into four types. The classification is shown in Table 3.

The above strategies include "rational" choice and "less rational" choice, it reflects players' "bounded rational”. Combining bank's and SME's initial strategies and reaction strategies can get $64(4 \times 4 \times 4)$ kinds combination strategies.

The combination principle is as Figure 1.

The bank's and SME's strategy set is:

$$
S=\{(0,0),(0,1),(1,0),(1,1)\}+\{\text { All-C,TFT, Anti-TFT, All-D }\}
$$

\subsection{Warehousing Company's "Predetermined Strategies"}

Warehousing company needs to make decisions when the SME is in default. The company is bank's coadjutant, and the reason that it becomes a mutineer is complex, random and unpredictable. Thus this paper regards warehousing company's misconduct as a random event.

Let $u$ and $1-u(u \in[0,1])$ denote the probabilities of warehousing company's conscientiousness and muting, respectively. Then the company's strategy set is $(1,0)$, which means (conscientiousness, muting). Thus the amount of warehousing company's strategy combination is $2^{n}, n \in \mathbb{Z}^{+}, n$ denotes the number of game.

During the simulation, using "rand” sentence in MATLAB to write the warehousing company's activity rules:

$$
\text { obj.Strategy }=\text { rand }<=\text { obj.PlayerTrustworthy. }
$$

It means let the computer generate a random number $\varepsilon^{\prime}(\in[0,1])$, if $\varepsilon^{\prime} \leq u$, the strategy is 1 ; But if $\varepsilon^{\prime}>u$, the strategy is 0 .

Thus, the total number of the game simulation is $2^{n+6}\left(64 \times 2^{n}\right)$.

\section{Table 3. Reaction strategies combination.}

\begin{tabular}{ccc}
\hline Reaction strategy & $p_{2}$ & $p_{3}$ \\
\hline Always keep faith strategy (A-F) & 1 & 1 \\
Tit-for-tat strategy (T-F-T) & 1 & 0 \\
Opportunistic strategy (O) & 0 & 1 \\
Always default strategy (A-D) & 0 & 0 \\
\hline
\end{tabular}




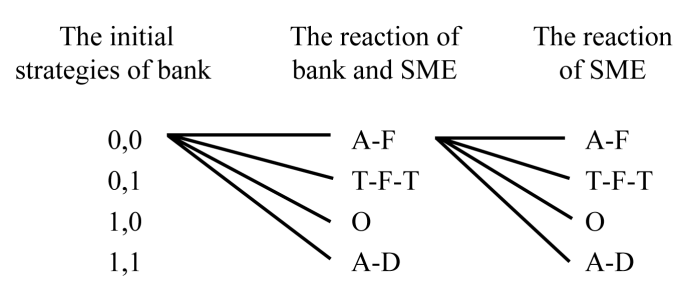

Figure 1. The combination principle of bank's and SME's strategies.

\section{The Realization of Game Simulation}

Although the bank and SME can have infinite credit operations, the operations usually just have 4 - 5 rounds in reality. So the game is just for four times. Thus the total number of the game simulates is 1024 .

In addition, in order to explain the model more intuitively, facilitate the computer processing and test whether the simulation program conforms to the reality, this paper gives numerical value to the game matrix.

\subsection{The Analysis of Simulation Results}

Setting $L^{\prime}=100, r_{0}=6.56 \%, C^{\prime}=1, R^{\prime}=20, T^{\prime}=130, Y^{\prime}=0.2, v^{\prime}=70 \%, F^{\prime}=2, H^{\prime}=3, G^{\prime}=6$.

1) The influences on bank and SME from warehousing company's strategy.

Warehousing company has 16 strategy combinations, here just discussing two different extremes: a) [1,1,1,1]; b) $[0,0,0,0]$. The simulation result is as Table 4 .

Then let computer simulates all scenario nouns, and depicting all bank's and SME's accumulated earning in the coordinate system (abscissa is SME's accumulated earning, ordinate is bank's).The result is shown in Figure 2 .

As Table 4 shown, when bank makes an advance to SME and SME default, warehousing company's muting reduces bank's and the system's total profit while raising SME'S accumulated earning.

As Figure 2 shown, after 4 round games, most of the system's accumulated earnings are in the negative range. Thus warehousing company's muting does not work for SME, and is inimical to improving the system's benefit.

2) The influences on bank and SME from SME's strategy

Bank's accumulated earning without regarding to bank sells off the pledge should be taken into account when measuring the real impact on bank from the strategy of SME. As can be seen from Table 4, the more the SME defaults, the lower the bank, the SME self and the system earn.

\subsection{The Control of SME's Default}

For a loan in practical operations, $L^{\prime}, C^{\prime}, Y^{\prime}$ and $v^{\prime}$ are determined, while $r_{0}, R^{\prime}$ and $T^{\prime}$ are undetermined. Therefore, changing the values of $r_{0}, R^{\prime}$ and $T^{\prime}$ respectively can obtain corresponding new simulation results. Thus we can know how to decrease the credit risk the bank faces.

1) The SME's accumulated earning by the loan would increase because of the increase of R. And the more times the SME gains the loan, the more the earning increases. To maximize the profits, SME tends to keep faith to get more loans if it can make huge benefit though the loan.

Then let the bank and SME select [1,1,1,1] and [0,0,0,0], respectively. Analyzing the effects that $r_{0}$ and $T$ have on the credit risk by comparing the results:

2) Keep other parameters remain the same, setting $r_{0}=10 \%$. (Lowering the loan rate is rare in practical operations so that this paper does not consider).

When the warehousing company selects conscientiousness and muting, SME's accumulated benefit are $-571>$ -585 and $-12>-26$, respectively. That is, upward fluctuation of the interest rate would increase the accumulated earning of SEM that is in default and then increase the loan default rate. It wouldn't benefit the credit risk control.

3) Keep other parameters remain the same, setting $T=140$.

When the warehousing company selects conscientiousness and muting, SME's accumulated profit are $-625<$ -585 and $-65<-26$, respectively. That is, increasing $T$ would decrease the accumulated earning of SEM that is in default and then decrease the loan default rate. It would benefit the credit risk control. 
Table 4. The simulation results of three-agent's four games.

\begin{tabular}{ccccccccc}
\hline & & \multicolumn{3}{c}{ Warehousing company's strategy $[1,1,1,1]$} & \multicolumn{2}{c}{ Warehousing company's strategy [0,0,0,0] } \\
\cline { 3 - 8 } & $\mathrm{B}$ & $\mathrm{C}$ & $\mathrm{D}$ & $\mathrm{E}$ & $\mathrm{F}$ & $\mathrm{C}$ & $\mathrm{E}$ & $\mathrm{F}$ \\
\hline$[0,1,1,1]$ & {$[0,0,1,1]$} & 40 & -102 & -119 & -79 & -102 & 21 & -82 \\
{$[0,1,1,1]$} & {$[0,1,0,0]$} & 70 & -216 & -279 & -209 & -216 & 1 & -215 \\
{$[0,1,1,1]$} & {$[0,0,0,0]$} & 100 & -329 & -439 & -339 & -329 & -19 & -348 \\
{$[0,0,1,1]$} & {$[0,1,1,1]$} & 7 & 7 & 27 & 35 & 7 & 27 & 35 \\
{$[0,1,1,0]$} & {$[0,0,1,1]$} & 37 & -106 & -132 & -96 & -106 & 7 & -99 \\
{$[1,1,1,1]$} & {$[1,1,1,1]$} & 14 & 14 & 55 & 69 & 14 & 55 & 69 \\
{$[1,0,1,0]$} & {$[0,1,0,1]$} & 67 & -219 & -292 & -226 & -219 & -12 & -232 \\
{$[1,1,1,1]$} & {$[0,0,0,0]$} & 133 & -438 & -585 & -452 & -438 & -26 & -464 \\
{$[1,0,0,0]$} & {$[0,1,1,1]$} & 33 & -110 & -146 & -112 & -110 & -6 & -115 \\
{$[0,1,1,1]$} & {$[1,1,1,1]$} & 11 & 11 & 41 & 52 & 11 & 41 & 52 \\
\hline
\end{tabular}

Notes: "A" means "Band’s strategy"; "B" means "SME's strategy"; "C" means "Band’s accumulated earning”; "D” means "Bank’s accumulated earning (without regard to bank sells off the pledge)"; "E” means "SME's accumulated earning”; "F” means "The bank's and SME's accumulated earning".

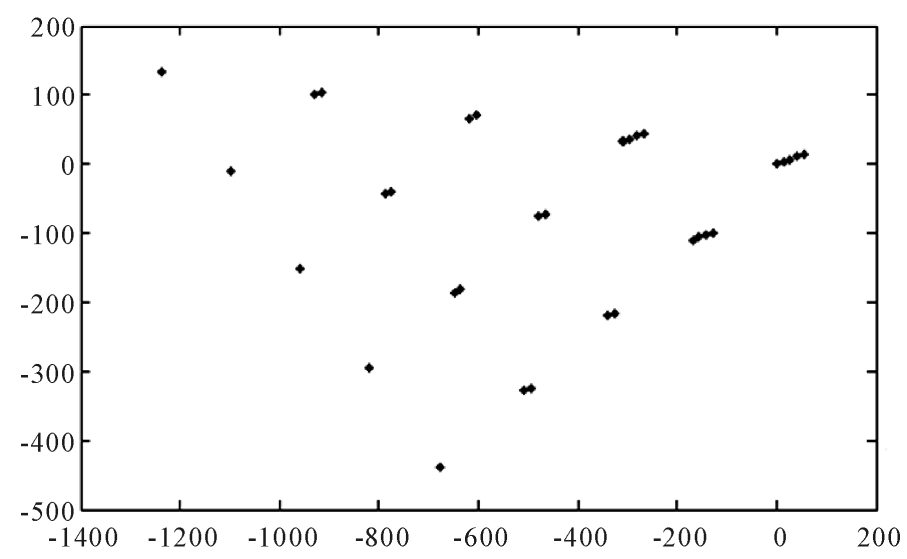

Figure 2. Bank's and SME'S accumulated earning.

\section{Conclusion}

This paper sets up a Bank-SME-Warehousing Company credit risk game model by using Game theory, predetermined strategies based on optimal reaction and considering participants' interplays, then using multi-agent simulation technique and taking MATLAB as the simulation platform to perform the game simulation. The results show that making an advance to SMEs with stronger profitability, enlarging penalty dynamics to SMEs that are in default and selecting warehousing company with responsibility can reduce credit risk of bank loan while increasing the system's benefit.

\section{References}

[1] Berger, A.N. and Asli, D.K. (2004) Bank Concentration and Conference: An Evolution in the Making a Conference Sponsored by the Federal Reserve Bank of Cleveland. Journal of Money, 6, 433-451. http://dx.doi.org/10.1353/mcb.2004.0040

[2] Busch, L. (2008) Supply Chain Finance: Flexibility and Ease of Implementation. Institutional Investor-International Edition, 1, 18-19.

[3] Kerr, J. (2006) Streamlining the Cash Flow. Supply Chain Management Review, 10, 25-31. 
[4] Camerinelli, E. (2009) Supply Chain Finance. Journal of Payments Strategy \& Systems, 3, 114-128.

[5] Buzacott, J.A. and Zhang, R.Q. (2004) Inventory Management with Asset-Based. Financing Management Science, 50, 1274-1292.

[6] Ma, J. (2008) Financing Model Analysis and Risk Control of Supply Chain Finance. Ph.D. Economics Thesis, Tianjin University, Tianjin.

[7] He, Y.Q. and Guo, T.T. (2010) Game Model Analysis of SMEs Financing Behavior Based on Supply Chain Financing Modes. Journal of Nanchang University (Engineering\& Technology), 6, 183-187.

[8] Wan, H.D. (2008) Supply Chain Finance Risk Model Analysis Study. On Economic Problems, 11, 109-111.

[9] Axelrod, R. (2007) The Evolution of Cooperation. Revised Edition, Wu J. Z. Shanghai People’s Publishing House, Shanghai.

[10] Zhang, T., Sun, L.Y. and Fang, C. (2002) A Study of Simulation in Repeated Game Based on the Evaluation of the Cumulative Aspiration Tense. Systems Engineering, 3, 87-91.

[11] Liu, J.J. and Wang, J.Y. (2007) Research of Simulation in Evolutionary Game Based on Multi-Agents. Computer \& Digital Engineering, 4, 1-3.

[12] Friedman, D. (1991) Evolutionary Games in Economics. Econometrics, 5, 637-666. 
Scientific Research Publishing (SCIRP) is one of the largest Open Access journal publishers. It is currently publishing more than 200 open access, online, peer-reviewed journals covering a wide range of academic disciplines. SCIRP serves the worldwide academic communities and contributes to the progress and application of science with its publication.

Other selected journals from SCIRP are listed as below. Submit your manuscript to us via either submit@scirp.org or Online Submission Portal.
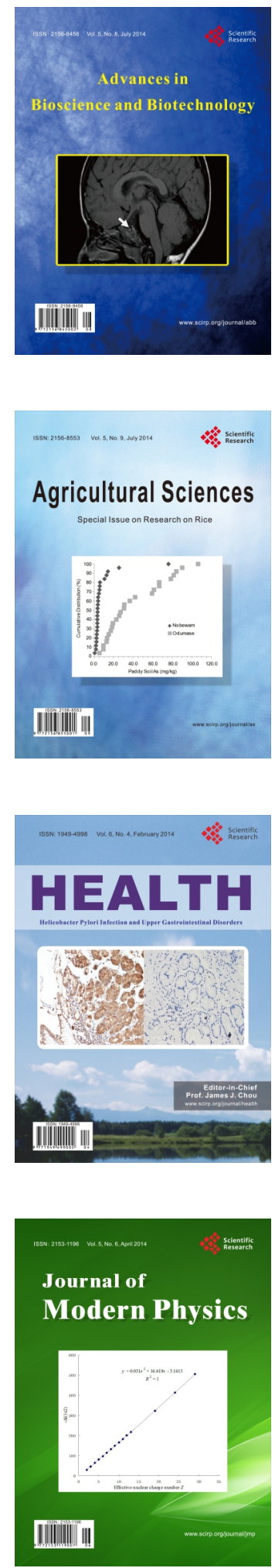
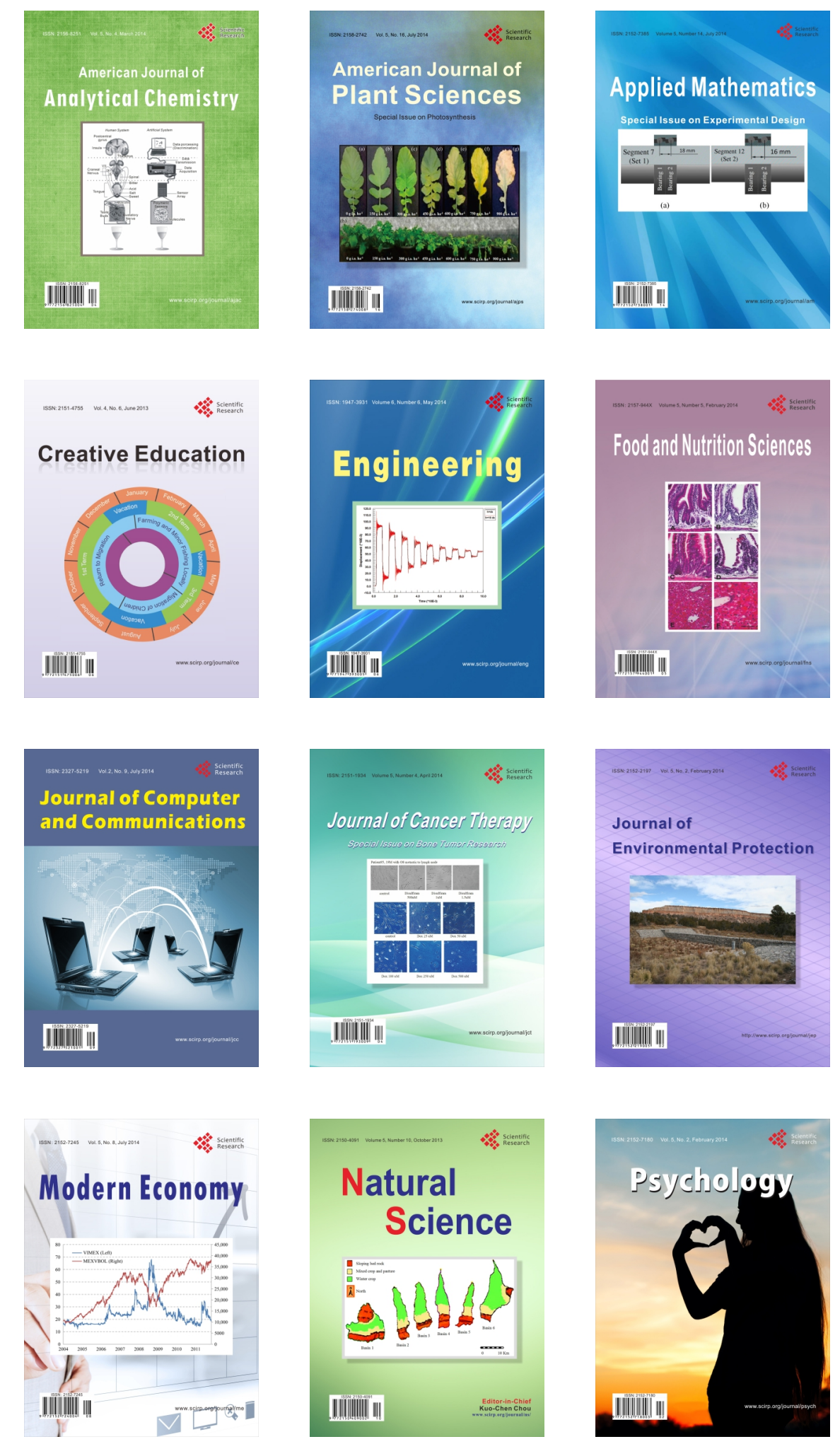